\title{
Inhibition of Smooth Muscle Cell Proliferation in Injured Rat Arteries Interaction of Heparin with Basic Fibroblast Growth Factor
}

\author{
Volkhard Lindner, " N. Eric Olson, * Alexander W. Clowes, ${ }^{\star}$ and Michael A. Reidy * \\ *Department of Pathology SJ-60; and ${ }^{\ddagger}$ Department of Surgery RF-25, University of Washington, Seattle, Washington 98195
}

\begin{abstract}
Heparin inhibits smooth muscle cell (SMC) proliferation after arterial injury by mechanisms that have yet to be defined. Since the initiation of SMC proliferation is mediated by basic fibroblast growth factor (bFGF), we have investigated the possibility that heparin inhibits SMC proliferation by displacing bFGF from the arterial wall. Using a rat carotid artery model of balloon catheter injury, we demonstrate that a bolus injection of heparin depletes the arterial wall of both systemically administered bFGF and of endogenous bFGF. Heparin, however, does not reduce the bFGF content of unmanipulated arteries. Further, a single injection of heparin given at the time of balloon injury reduces SMC proliferation by $55 \%$ but has no effect when given $6 \mathrm{~h}$ after injury. SMC proliferation induced in a denuded artery by injection of bFGF is inhibited almost completely by a bolus injection of heparin; however, pretreatment with a bolus of heparin does not prevent SMC from responding to a subsequent bolus of bFGF. These experiments suggest that heparin can inhibit SMC proliferation in part by removal of released bFGF from sites of injury. (J. Clin. Invest. 1992. 90:2044-2049.) Key words: angioplasty • basic fibroblast growth factor • extracellular matrix • heparin • smooth muscle
\end{abstract}

\section{Introduction}

A common problem after angioplasty is the occurrence of restenosis $(1,2)$, which is mediated in part by proliferation of vascular smooth muscle cells (SMC) ${ }^{1}$. Much attention has focused on understanding the processes involved in the proliferation of arterial SMCs (3-5) and we have recently found that SMC replication is significantly inhibited $(>80 \%)$ by an antibody to basic fibroblast growth factor (bFGF) (6) in an injury model of the rat carotid artery. This observation demonstrates that bFGF released from damaged cells is responsible for the initiation of medial SMC proliferation.

Heparin has been shown to be an effective inhibitor of SMC proliferation and intimal thickening in the ballooned rat carotid artery (7-11). How heparin inhibits SMC proliferation is still unclear. It is known that heparin binds to bFGF, forming a

Address correspondence to Volkhard Lindner, M.D., Ph.D., School of Medicine, Department of Pathology SJ-60, University of Washington, Seattle, WA 98195. 1992.

Received for publication 7 January 1992 and in revised form 1 May

1. Abbreviations used in this paper: bFGF, basic fibroblast growth factor; BrdU, 5-bromo-2'-deoxy-uridine; SMC, smooth muscle cell.

J. Clin. Invest.

(C) The American Society for Clinical Investigation, Inc.

$0021-9738 / 92 / 11 / 2044 / 06 \$ 2.00$

Volume 90, November 1992, 2044-2049
bFGF-heparin complex and protecting the growth factor from degradation (12). In culture, bFGF can be displaced from extracellular matrix binding sites by heparin $(13,14)$, and in vivo, bFGF displaced by this mechanism could then be cleared through metabolic pathways in the liver and kidney (15). Thus, in vivo heparin might displace bFGF from its matrix binding sites and clear it from the artery wall. The aim of these experiments was to study the interaction of heparin with bFGF and investigate the mechanism of how heparin inhibits SMC proliferation after balloon injury in vivo.

\section{Methods}

Male Sprague-Dawley rats (3-4 mo old) from Tyler Laboratories, Bellevue, WA, were used in all the experiments. All surgical procedures were carried out under general anesthesia by intraperitoneal injection of xylazine ( $2.2 \mathrm{mg} / \mathrm{kg}$, AnaSed; Lloyd Laboratories, Shenandoah, IA) and ketamine $(50 \mathrm{mg} / \mathrm{kg}$ body wt, Ketaset; Aveco Co., Inc., Fort Dodge, IA).

Labeling of $b F G F$. Human recombinant $b F G F$ was a generous gift from Synergen Inc., Boulder, CO. It was labeled with ${ }^{125}$ I (IMS30, 100 $\mathrm{mCi} / \mathrm{ml}$; Amersham Corp., Arlington Heights, IL) using Iodo-Beads (Pierce Chemical Co., Rockford, IL) following the manufacturer's instructions. The rest of the labeling procedure was carried out as described (16). The specific activity of the labeled bFGF used was $\sim 27$ and $\sim 65 \mathrm{cpm} / \mathrm{fmol}$, respectively.

${ }^{125} I-b F G F$ in the vessel wall. The left common carotid artery and segments of the thoracic aorta in rats were denuded of endothelium with a $2 \mathrm{~F}$ Fogarty balloon catheter as described (17). Five weightmatched pairs of rats were then injected with equal amounts of ${ }^{125} \mathrm{I}$ $\mathrm{bFGF}(60 \mu \mathrm{g}$ per rat $)$ diluted in $0.2 \mathrm{ml}$ of saline. At the indicated times after ${ }^{125} \mathrm{I}-\mathrm{bFGF}$ injection, blood samples were drawn by tail vein cannulation and the radioactivity of a 50 - $\mu$ l plasma sample was measured in a gamma counter (Gamma 5500; Beckman Instruments, Fullerton, CA). 45 min after injection of the radiolabel one rat of each pair received 250 US Pharmacopeia units of standard heparin ( $\geq 140$ USP units/mg; LyphoMed, Rosemont, IL) intravenously while the corresponding control animal was injected with an equal volume of saline. Blood samples were obtained for measuring ${ }^{125}$ I-bFGF levels, and 60 min after the heparin/saline administration, the animals were injected with a solution of $5 \%$ Evans blue $(0.3 \mathrm{ml}$ in saline $)$ to mark the denuded areas. 10 min later the animals were killed, perfused with lactated Ringer's solution, and then perfusion-fixed with $4 \%$ paraformaldehyde in $0.1 \mathrm{M}$ phosphate buffer ( $\mathrm{pH} 7.3$ ). The left carotid artery and thoracic aorta were excised, adhering loose connective tissue was removed, and the denuded segments (blue) and the endothelialized segments of the thoracic aorta were separated. The tissue pieces were airdried and the amount of radiolabel was then quantitated separately in at least three pieces of each denuded carotid, denuded aorta, and endothelialized aorta. The data ( $\mathrm{cpm} / \mathrm{mg}$ dry wt of tissue) obtained from the animals injected with heparin were expressed as a percentage of the activity measured in the corresponding control animals which had received saline. Paired Student's $t$ test was used to compare the results.

Endogenous bFGF in the vessel wall. Groups of three rats received either a bolus injection of heparin ( 888 USP units/ $\mathrm{kg}$ body wt) or an equivalent volume of saline intravenously immediately before surgery. 
Endothelial denudation of the left carotid artery was achieved using three passes of an inflated $2 \mathrm{~F}$ Fogarty catheter, which damages the medial SMC substantially $(18,19)$. In sham-operated rats all surgery was performed, with the exception of endothelial denudation. $9 \mathrm{~h}$ after surgery, all rats were killed and their left carotid arteries were processed for immunoblotting or quantitation of bFGF using an immunodetection assay as described below. The data presented here reflect representative results from three independent experiments.

Immunoblotting. Processing of the tissue and immunoblotting were performed as recently described (20). Briefly, carotid arteries were excised, adhering connective tissue was removed, and the vessels were snap frozen in liquid nitrogen. Three carotid arteries that had been treated in an identical manner were pooled for each sample. The vessels were pulverized under liquid nitrogen with a mortar and pestle and the samples were vortexed in ice-cold cell lysis buffer containing $0.5 \% \mathrm{SDS}, 50 \mathrm{mM}$ Tris, $1 \mu \mathrm{M}$ PMSF, and $10 \mu \mathrm{g} / \mathrm{ml}$ leupeptin. Insoluble matter was removed by centrifugation at $13,500 \mathrm{~g}$. A small sample of the resulting supernatant was reserved for protein determination; the rest was diluted $1: 1$ in sample buffer $(0.1 \mathrm{M}$ Tris pH $6.8,2 \%$ SDS, $20 \%$ glycerol, $0.002 \%$ Bromphenol blue, $5 \% \beta$-mercaptoethanol) and boiled for $5 \mathrm{~min}$. The protein concentration of each sample was determined using a bicinchoninic acid assay (Pierce Chemical Co., Rockford, IL) with bovine serum albumin (BSA) as a standard. Equal amounts of total protein were loaded onto a $12 \%$ polyacrylamide gel, electrophoresed and transferred to nitrocellulose. Prestained molecular weight standards (BioRad Laboratories, Richmond, CA) were used as reference markers. The blot was then immunostained with a monoclonal antibody against bFGF (DE6) $(1 \mu \mathrm{g} / \mathrm{ml})$ which is described elsewhere (21). The antibody was kindly provided by Dr. Tom Reilly (DuPontMerck Co., Wilmington, DE). A secondary biotinylated horse antimouse IgG (rat-absorbed; Vector Laboratories Burlingame, CA) was used at a 1:200 dilution. Otherwise an identical protocol as previously described was followed (5). Identical blots were also stained with nonimmune IgG.

Immunodetection assay for $b F G F$. Carotid arteries from individual animals ( $n=3$ per group) were separately processed as described for immunoblotting, and test samples with an equal protein concentration were assayed for bFGF by diluting the cell lysate $1: 10$ with phosphate buffered saline (PBS). At this dilution the SDS did not interfere with the assay. Wells of a 96-well plate (EIA/RIA plate; Costar Corp., Cambridge, MA) were coated overnight at $4^{\circ} \mathrm{C}$ with the mouse monoclonal antibody against bFGF (DE6) (21) at a concentration of $4 \mu \mathrm{g} / \mathrm{ml}$ in PBS. All subsequent incubations were carried out at room temperature for $1 \mathrm{~h}$ and 3 rinses, with 0.5\% BSA in PBS following each incubation. All antibodies were diluted in $1 \%$ BSA in PBS. Nonspecific binding was blocked with $1 \%$ BSA in PBS containing $2 \%$ normal goat serum. Standard dilutions of human recombinant bFGF and test samples (both in triplicate) were then allowed to incubate in the wells, followed by incubation with an affinity-purified polyclonal rabbit antibody against $\operatorname{bFGF}(1 \mu \mathrm{g} / \mathrm{ml})$. This antibody is described elsewhere $(5,6)$. Incubation with a biotinylated goat anti-rabbit IgG antibody (Vector Laboratories, 1:400) was followed by labeling the antibody with peroxidase using an avidin-biotin complex (ABC Elite; Vector Laboratories). The complex was visualized using $\sigma$-phenylenediamine $(1 \mathrm{mg} / \mathrm{ml}$ in $0.1 \mathrm{M}$ sodium citrate, $\mathrm{pH} 4.5$ ). The color reaction was stopped after $30 \mathrm{~min}$ with $4.5 \mathrm{M}$ sulfuric acid. Absorbance was then measured at $490 \mathrm{~nm}$ using an ELISA reader (Bio-Tek Instruments, Winooski, VT). The concentrations of bFGF in the samples were then calculated using the mean of the triplicate measurements and the standard curve obtained with the recombinant bFGF. The detection limit for bFGF was approximately $0.1 \mathrm{ng} / \mathrm{ml}$.

Proliferation of SMC. ( $a$ ) Immediately before surgery groups of rats received either 888 USP units of standard heparin (LyphoMed) or an equivalent amount of vehicle intravenously. The left carotid artery was then denuded by balloon catheterization as described above. Labeling of proliferating SMC was carried out using the thymidine analogue 5-bromo-2'-deoxy-uridine (BrdU) (Boehringer Mannheim Corp., Indianapolis, IN). Three injections (each $25 \mathrm{mg} / \mathrm{kg}$ body wt in saline) were given subcutaneously 28,36 , and $44 \mathrm{~h}$ after injury. $2 \mathrm{~h}$ after the last BrdU injection the animals were killed with an overdose of sodium pentobarbital $(160 \mathrm{mg} / \mathrm{kg}$ body wt; Anthony Products Co., Arcadia, CA). Fixation for $5 \mathrm{~min}$ by perfusion with $4 \%$ paraformaldehyde in 0.1 M sodium phosphate buffer ( $\mathrm{pH} 7.3$ ) was followed by excision of the carotid arteries and immersion fixation for $2 \mathrm{~h}$. From the central portion of the carotid arteries, three segments, $4 \mathrm{~mm}$ apart, were embedded in paraffin and cross-sections were cut. Proliferating SMC were identified by using a monoclonal antibody against BrdU (Boehringer Mannheim Corp., Indianapolis, IN) and a protocol was followed as described (22). The number of stained nuclei was counted and the BrdU labeling index ([stained nuclei/total nuclei] $\times 100$ ) was calculated. $(b)$ The experiment was repeated in sets of animals following the identical protocol as described above, with the exception that the administration of heparin/vehicle was delayed until $6 \mathrm{~h}$ after surgery. Labeling with BrdU and processing of the tissue was carried out as described in $a$. (c) Two groups of rats had their left carotid artery denuded with a filament loop as described (18). Immediately after surgery, all rats received $60 \mu \mathrm{g}$ bFGF (kindly provided by Synergen Inc.,) intravenously via tail vein injection. 15 min later, standard heparin ( 888 USP units $/ \mathrm{kg}$ ) was injected intravenously into the animals of the experimental group while the control group received vehicle, and labeling with $\mathrm{BrdU}$ was performed as described above. (d) Two groups of rats received either standard heparin ( 888 USP units $/ \mathrm{kg}$ ) or vehicle intravenously immediately before denudation of their left carotid arteries with a filament loop. $6 \mathrm{~h}$ later (at that time the whole blood clotting time had returned to normal ), $60 \mu \mathrm{g}$ of bFGF was administered to both groups via tail vein injection. Labeling with $\mathrm{BrdU}$ and processing of the tissue was otherwise carried out as described under $a$.

All proliferation data were analyzed using Student's $t$ test. Data were considered significant if $P<0.05$.

\section{Results}

Distribution of exogenous ${ }^{125} I-b F G F$. The left carotid artery and segments of the thoracic aorta in groups of rats were denuded of endothelium by balloon catheterization. The clearance of ${ }^{125}$ I-labeled bFGF (Fig. $1 \mathrm{~A}$ ) from the circulation of those rats was then measured after intravenous injection of 60 $\mu \mathrm{g}^{125} \mathrm{I}$-bFGF into the tail vein of each rat. After an initially very rapid clearance $(15,23)$ a low-level plateau of ${ }^{125}$ I-bFGF was reached $15 \mathrm{~min}$ after the injection. Immediately after the injection of heparin there was a dramatic increase in ${ }^{125} \mathrm{I}$-bFGF plasma levels with a concomitantly prolonged half-life of the radiolabel $\left(t_{1 / 2} \sim 50 \mathrm{~min}\right)$. The highest levels were observed within 5 min after the heparin injection and vehicle had no effect on ${ }^{125}$ I-bFGF plasma levels.

$75 \mathrm{~min}$ after the injection of heparin or saline in the above experiment, the animals were injected with Evans blue and then killed. Denuded areas of the thoracic aorta and carotid artery could therefore readily be identified. This allowed us to determine the amount of radioactively labeled bFGF present in the vessel wall both in normal (endothelialized) and denuded arterial tissue. In saline-treated animals, the amount of radiolabel detected in deendothelialized aortic tissue was $\sim 45$-fold higher when compared to endothelialized aortae (Fig. $1 B$ ). Fig. $1 C$ shows the amount of ${ }^{125}$ I-bFGF measured in the arterial tissue after heparin injection, expressed as a percentage of the vehicle control. Heparin caused a significant reduction in ${ }^{125}$ I-bFGF bound to both denuded carotid artery $(\sim 66 \%$ of control value) and denuded aorta ( $\sim 55 \%$ of control value) when compared to animals that received ${ }^{125}$ I-bFGF followed by vehicle injection. Interestingly, heparin increased the binding of ${ }^{125} \mathrm{I}$-bFGF in untraumatized aortae (approximately $220 \%$ of 
$\mathbf{A}$

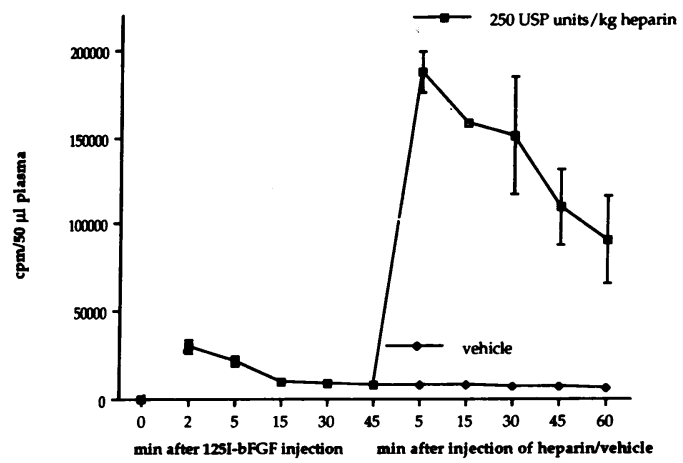

B
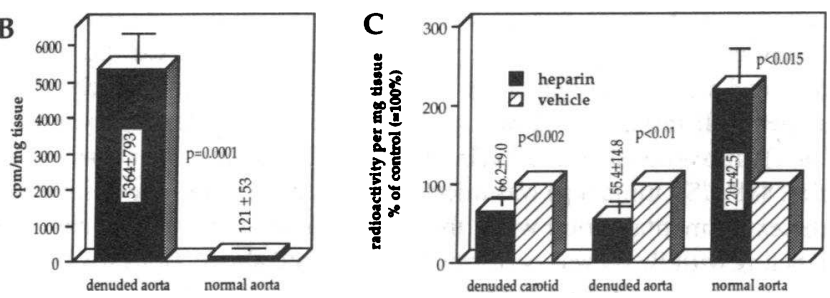

Figure 1. Rats were injected with $60 \mu \mathrm{g}{ }^{125} \mathrm{I}-\mathrm{bFGF}$ and $45 \mathrm{~min}$ later heparin/saline was administered intravenously. 75 min later, animals were killed and the radioactivity measured in the indicated tissues. $(A)$ Plasma levels of the radiolabel were measured at the indicated times. Note that within 2 min most of the ${ }^{125}$ I-bFGF is already lost from the circulation and heparin causes an immediate increase of circulating ${ }^{125} \mathrm{I}-\mathrm{bFGF}$ with a prolonged half-life. Means $\pm \mathrm{SD}, n=3$ animals per group. $(B) 2 \mathrm{~h}$ after injection of ${ }^{125} \mathrm{I}-\mathrm{bFGF}$ and vehicle administration an approximate 45 -fold increase in radioactivity was found in the denuded aorta. Means $\pm \mathrm{SD}, n=4$ animals in each group. (C) Radioactivity in the indicated tissues after heparin injection is expressed as a percentage of controls $(100 \%)$. which received ${ }^{125} \mathrm{I}-$ bFGF and vehicle. Heparin significantly reduced the amount of labeled bFGF in denuded arteries, but binding to endothelialized vessels was increased by heparin. Means \pm SE of two separate experiments with a total of five animals in each group.

control value, Fig. $1 C$ ) which is possibly related to heparin's ability to bind to endothelial cells (24).

Heparin and endogenous bFGF in the rat carotid artery. In the experiments described above, heparin was found to displace exogenously added bFGF from a denuded artery. However, this result does not allow us to draw conclusions regarding the fate of endogenous bFGF. We therefore attempted to determine whether heparin injection after balloon catheter denudation causes a reduction in the amount of detectable endogenous bFGF in the carotid artery. Basic FGF purified from tissue is prone to degradation with subsequent loss of biological activity. We minimized degradation by avoiding any unnecessary purification steps. Immunoblot assays were used to semiquantitatively measure the bFGF content in the vessel wall and to discriminate between the different molecular weight forms of bFGF. In all the experiments the predominant species of bFGF had an apparent molecular mass of $23 \mathrm{kD}$, which is in agreement with previous data (20). When a single injection of heparin was given before balloon catheter injury of the carotid artery, a marked reduction in the amount of detectable bFGF was apparent $9 \mathrm{~h}$ after injection (Fig. $2 A$, lane 4 vs. 5). In unmanipulated arteries, injection of heparin caused no obvious loss of endogenous bFGF from those vessels (Fig. $2 A$, lane
2 vs. 3). Using an immunodetection assay we were able to measure directly the concentrations of bFGF in the vessel wall (Fig. 2 B). After balloon catheter denudation, bFGF levels were reduced to $\sim 20 \%$ of the controls, and after an injection of heparin, the concentrations of bFGF in balloon injured vessels were below the detection limit. Heparin caused no signifcant loss of bFGF in unmanipulated vessels (Fig. $2 B$ ). These findings demonstrate that heparin removes bFGF from traumatized arteries.

Heparin and SMC proliferation. Since a bolus injection of heparin is able to displace bFGF in injured arteries, heparin might be expected to inhibit the proliferative response of SMCs. A bolus injection of heparin ( 888 USP units $/ \mathrm{kg}$ ) was administered to rats before balloon catheterization of the carotid artery and medial SMC proliferation was determined $2 \mathrm{~d}$ later using immunocytochemistry and the thymidine analogue BrdU. Fig. $3 A$ shows that a single injection of heparin given at the time of injury causes a significant reduction in SMC proliferation ( $9 \%$ vs. $20.3 \%$ in control animals). When heparin ad-

A

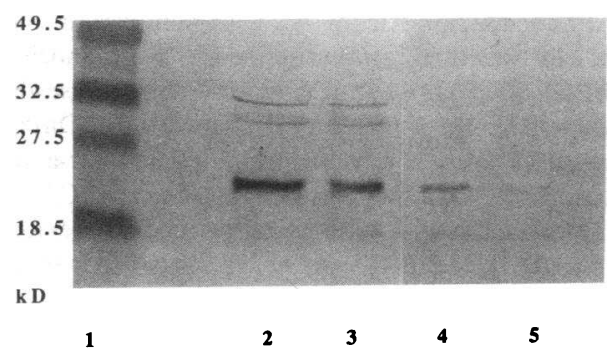

B

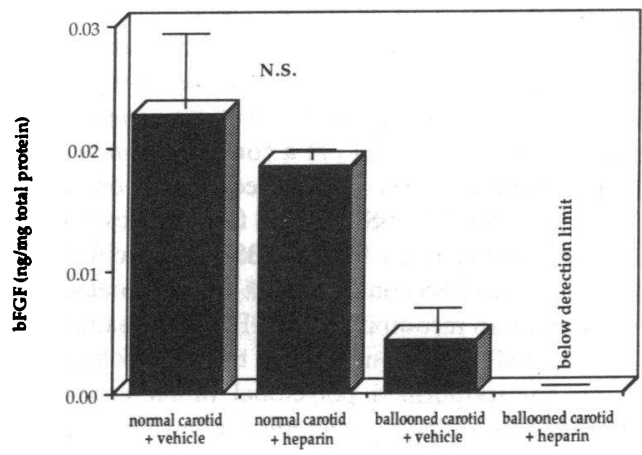

Figure 2. Endogenous bFGF in tissue lysates from rat carotid arteries obtained $9 \mathrm{~h}$ after denudation and injection of vehicle or heparin ( 888 USP units/kg before injury). ( $A$ ) Immunoblot using a monoclonal antibody against bFGF. Lane 1 : prestained molecular weight standards (lysozyme $18.5 \mathrm{kD}$, soybean trypsin inhibitor $27.5 \mathrm{kD}$, bovine carbonic anhydrase $32.5 \mathrm{kD}$, ovalbumin $49.5 \mathrm{kD}$ ). Equal amounts of protein were loaded on lanes 2-5. Lane 2: lysate from normal carotid arteries after vehicle injection and after heparin injection (lane 3). Lane 4: lysate from carotid arteries after balloon catheter injury and vehicle injection or heparin injection (lane 5). Note the marked reduction in bFGF after injury and heparin injection. Molecular masses are indicated on the left. $(B)$ Immunodetection assay for bFGF. Basic FGF was not detectable in balloon-injured arteries after heparin injection (detection limit $0.0009 \mathrm{ng} / \mathrm{mg}$ total protein) while corresponding vehicle injection showed an approximate $80 \%$ reduction compared to normal vessels. Heparin had no effect on normal vessels. Means $\pm \mathrm{SD}$ of 3 separate experiments are shown. 

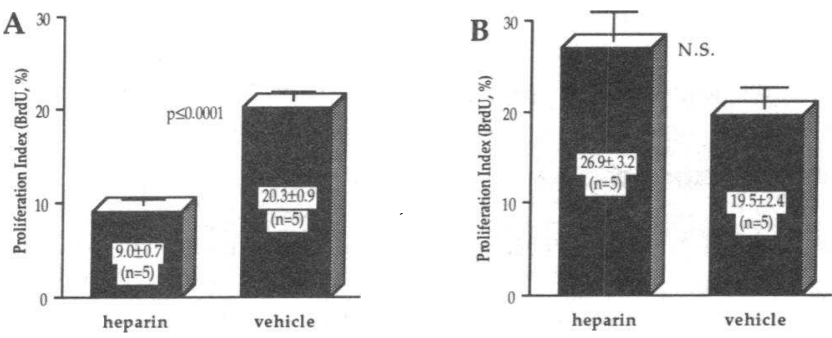

Figure 3. Proliferation of medial SMC in the rat carotid artery $46 \mathrm{~h}$ after balloon catheter denudation and treatment with a bolus injection of heparin ( 888 USP units $/ \mathrm{kg}$ ) or vehicle. Labeling of proliferating cells was carried out by injecting three doses of the BrdU thymidine analogue (28, 36, and $44 \mathrm{~h}$ after injury). Proliferating SMC were identified by positive staining with an antibody against BrdU. The number of proliferating SMC are expressed as a percentage of the total number of SMC per cross section. Data represent means \pm SE. $(A)$ A bolus injection of heparin was given immediately before injury. Heparin caused a significant reduction in SMC proliferation. (B) A bolus injection of heparin was given $6 \mathrm{~h}$ after injury. No significant difference was found between vehicle and heparin treated animals.

ministration was delayed for $6 \mathrm{~h}$ after balloon injury, no reduction in SMC proliferation was observed $2 \mathrm{~d}$ later (Fig. $3 \mathrm{~B}$ ).

Subsequently we attempted to demonstrate that inhibition of SMC proliferation by heparin is mediated by antagonizing the cellular response to bFGF. Groups of rats had their carotid arteries denuded with the filament loop and immediately after surgery, $60 \mu \mathrm{g}$ i.v. of bFGF was injected. $15 \mathrm{~min}$ later, when most of the bFGF was cleared from circulation (Fig. $1 A$ ), one group of rats received a bolus injection of heparin while the control group received vehicle. The proliferation in response to exogenous bFGF was almost completely abolished by the bolus injection of heparin (SMC proliferation $3.5 \%$ vs. $21.9 \%$ in the control group) (Fig. $4 A$ ).

One possibility is that heparin inhibits SMC proliferation by acting directly on the ability of SMC to enter the cell cycle $(25,26)$. We addressed this issue with the following experiment. Immediately before denudation of their carotid artery with the filament loop, groups of rats were injected with a bolus of heparin or vehicle. $6 \mathrm{~h}$ later, when the heparin was cleared, both groups received an intravenous injection of $60 \mu \mathrm{g}$ of bFGF. SMC proliferation was measured in an identical time period as for the experiments above. As shown in Fig. $4 B$, SMC proliferation was nearly identical in the two groups. These data demonstrate that pretreatment with heparin does not impair the ability of a denuded vessel to respond to bFGF.

\section{Discussion}

Heparin inhibits the SMC proliferation and intimal thickening that develops after balloon catheter injury of an artery (7-11), but the mechanism of this inhibition has remained unclear. We have suggested that bFGF released from damaged SMC is responsible for initiation of subsequent SMC proliferation (6) and it is known that bFGF bound to extracellular matrix can be displaced by heparin $(13,14)$. These observations prompted us to investigate the interaction of heparin with bFGF in the vessel wall. In the present paper we provide evidence that heparin removes bFGF from injured arteries and this mechanism may be responsible for the inhibition of medial SMC proliferation.

${ }^{125} \mathrm{I}-\mathrm{bFGF}$ injected into rabbits is cleared rapidly from the circulation and Thompson et al. (27) noted that heparin caused the reappearance of ${ }^{125} \mathrm{I}-\mathrm{bFGF}$ in the plasma. Additional heparin injections did not increase the bFGF plasma concentration. Similar results were obtained in our rat model. We noted that the increase in ${ }^{125} \mathrm{I}-\mathrm{bFGF}$ plasma concentration was maximal within $5 \mathrm{~min}$ after heparin injection and the plasma half-life was approximately $50 \mathrm{~min}$. Presumably the ${ }^{125}$ I-bFGF was cleared by metabolic pathways in liver and kidney and the accumulation of radiolabel in the urine supports this (data not shown).

Injection of ${ }^{125}$ I-bFGF allowed us to measure the amount of radiolabel in untraumatized as well as denuded vessels. Compared to normal arteries, approximately 45 -fold more radioactivity was measured in denuded vessels, which suggests that an intact endothelium does indeed function as a barrier reducing the deposition of bFGF into the matrix of the vessel wall. This observation provides a possible explanation for the lack of SMC proliferation in response to infused bFGF in endothelialized arteries (5). An important finding in our attempt to understand heparin/bFGF interaction is that an injection of heparin removes ${ }^{125} \mathrm{I}-\mathrm{bFGF}$ from denuded arteries. This finding is in accordance with in vitro data $(13,14)$, which demonstrated that heparin can compete with low affinity binding sites (matrix) for bFGF. Interestingly, heparin causes increased binding of ${ }^{125} \mathrm{I}$-bFGF to endothelialized vessels. One possible explanation for this finding might be related to binding of the heparin${ }^{125} \mathrm{I}-\mathrm{bFGF}$ complex via heparin binding sites on the endothelial cells since endothelial cells can bind heparin directly (24).

We also show that heparin causes substantial loss of endogenous bFGF from carotid arteries injured by balloon catheterization and significantly reduces SMC proliferation. In contrast, heparin did not reduce the amount of bFGF in the wall of normal arteries. The fact that heparin was only able to remove bFGF from arteries which were traumatized argues indirectly that bFGF is not present in the extracellular matrix of uninjured arteries. This finding is in agreement with our immunocytochemical staining which reveals predominantly nuclear and cellular localization of bFGF in uninjured rat carotid arteries (6) and a loss of specific cellular staining after balloon injury
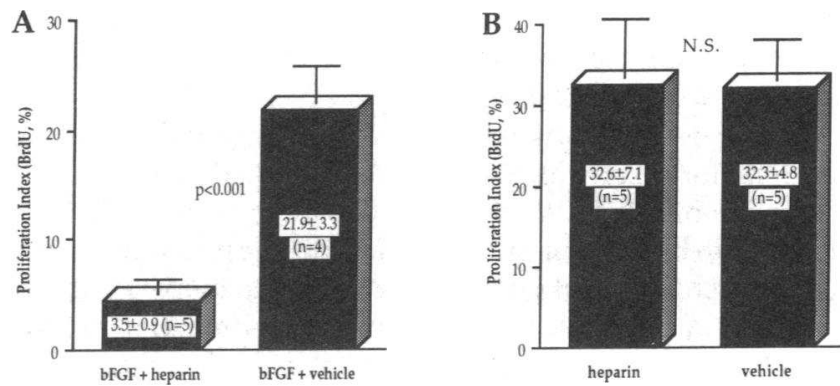

Figure 4. Proliferation of medial SMC in the rat carotid artery $46 \mathrm{~h}$ after denudation with a filament loop and treatment with a bolus injection of heparin ( $888 \mathrm{USP}$ units $/ \mathrm{kg}$ ) or vehicle. Labeling of proliferating cells was carried out in an identical way as described for Fig. 3. Data represent mean \pm SE. $(A)$ All animals received an intravenous injection of bFGF $(60 \mu \mathrm{g})$ immediately after denudation. 15 min later either a bolus injection of heparin or vehicle was administered. Heparin significantly inhibited the proliferative response to bFGF. ( $B$ ) Heparin or vehicle was administered before denudation. $6 \mathrm{~h}$ later all rats received $60 \mu \mathrm{g}$ bFGF i.v. Pretreatment with heparin did not impair the ability of SMC to respond to bFGF. 
(20). $9 \mathrm{~h}$ after balloon injury, an approximate $80 \%$ loss of endogenous bFGF from the vessel wall was found. It is likely that at least part of this injury-mediated loss reflects metabolism by medial SMC which have entered the cell cycle as well as spontaneous loss due to washout into the circulation. Further, the data suggest that most of the residual bFGF $(\sim 20 \%)$ is bound to the extracellular matrix since no detectable levels of bFGF were found in balloon-injured carotid arteries from animals treated with heparin. In vitro, Flaumenhaft et al. (28) have shown that matrix-bound bFGF acts as a long-term stimulator of DNA synthesis and plasminogen activator production by endothelial cells. Basic FGF released into the matrix of arteries after injury may play a similar role in inducing SMC proliferation and migration into the intima. In this regard it is interesting to note that in cultured SMCs, heparin was found to inhibit tissue-type plasminogen activator expression (29) which is thought to play a role in SMC migration $(30,31)$ and intimal thickening. The proliferative response of SMC to arterial injury appears to correlate with the amount of medial SMC damage caused by the denuding technique ( $13.6 \%$ after balloon injury vs. $1.4 \%$ after filament denudation) (18), which supports our suggestion that injury releases bFGF into extracellular sites. The proliferative response of SMCs after filament loop denudation of the rat carotid artery is very low but subsequent administration of bFGF increases SMC proliferation (Fig. 4, $A$ ) (5). In this study we anticipated that heparin would interact directly with exogenous bFGF and thereby would reduce bFGF-mediated SMC proliferation. A bolus of heparin almost completely inhibited the bFGF-induced response, suggesting that heparin inhibits SMC replication by displacing bFGF (Fig. $4 A$ ).

Of interest is the apparent discrepancy between the substantial reduction in endogenous bFGF after heparin injection and the estimated $25 \%$ loss of DNA caused by balloon catheterization (19). These data suggest that more bFGF seems be released than can be accounted for by cell death. One conclusion is that bFGF can be released from sublethally damaged SMC. Muthukrishnan et al. (32) have recently demonstrated that bFGF is indeed released very efficiently after a nonlethal injury to cells. The release of bFGF after injury is not unique to arteries since a recent report shows that a similar situation exists in the cornea where corneal epithelial cells stain positive for bFGF, and the protein is detected in the underlying basement membrane only after lytic cell injury (33).

One possibility is that heparin acts directly on the cells and its inhibitory action on SMC replication would be unrelated to clearance of bFGF. We therefore tested the ability of SMC to respond to bFGF after pretreatment with heparin. Heparin was administered and bFGF was injected after the whole blood clotting time had returned to normal. Determination of SMC proliferation at an identical time point as in the other experiments above revealed that the ability of SMC to respond to exogenous bFGF was not at all reduced after pretreatment with heparin. The data presented here do not rule out the possibility that heparin inhibits SMC proliferation by mechanisms unrelated to bFGF. Majesky et al. (25) reported that heparin administered by continuous infusion inhibited SMC proliferation even when started as late as $18 \mathrm{~h}$ after balloon injury. Since heparin inhibits the expression of a variety of genes (29) it is likely that it has one or more other effects which account for inhibition of SMC migration and intimal thickening. All the experiments in this study, however, are consistent with the hypothesis that inhibition by heparin of initial SMC proliferation in injured arteries is due to removal of released bFGF.

\section{Acknowledgments}

We wish to thank Dr. Christopher Jackson for stimulating discussions regarding the design of the experiments. We also like to thank Lisa Stiffler and Jeff Kozlowski for their excellent technical assistance.

This study was supported by grants HL-41 103, HL-03174, and HL42270 from the National Institutes of Health.

\section{References}

1. Holmes, D. R., R. E. Vlietstra, H. C. Smith, G. W. Vetrovec, K. M. Kent, M. J. Cowley, D. P. Faxon, A. R. Gruentzig, S. F. Kelsey, K. M. Detre et al. 1984. Restenosis after percutaneous transluminal coronary angioplasty (PTCA): A report from the PTCA Registry of the National Heart, Lung and Blood Institute. Am. J. Cardiol. 53:27c-31c.

2. Leimgruber, P. P., G. S. Roubin, J. Hollman, G. A. Cotsonis, B. Meier, J. S. Douglas, S. B. King, and A. R. Gruentzig. 1986. Restenosis after successful coronary angioplasty in patients with single-vessel disease. Circulation. 73:710-717.

3. Majesky, M. W., V. Lindner, D. R. Twardzik, S. M. Schwartz, and M. A. Reidy. 1991. Production of transforming growth factor $\beta 1$ during repair of arterial injury. J. Clin. Invest. 88:904-910.

4. Majesky, M. W., M. A. Reidy, D. F. Bowen-Pope, C. E. Hart, J. N. Wilcox, and S. M. Schwartz. 1990. PDGF ligand and receptor gene expression during repair of arterial injury. J. Cell Biol. 111:2149-2158.

5. Lindner, V., D. A. Lappi, A. Baird, R. A. Majack, and M. A. Reidy. 1990. Role of basic fibroblast growth factor in vascular lesion formation. Circ. Res. 68:106-113

6. Lindner, V., and M. A. Reidy. 1991. Proliferation of smooth muscle cells after vascular injury is inhibited by an antibody against fibroblast growth factor. Proc. Natl. Acad. Sci. USA. 88:3739-3743.

7. Clowes, A. W., and M. J. Karnovsky. 1977. Suppression by heparin of smooth muscle cell proliferation in injured arteries. Nature (Lond.). 265:625626.

8. Clowes, A. W., and M. M. Clowes. 1985. Kinetics of cellular proliferation after arterial injury. II. Inhibition of smooth muscle cell growth by heparin. Lab. Invest. 52:611-616.

9. Guyton, J. R., R. D. Rosenberg A. W. Clowes, and M. J. Karnovsky. 1980. Inhibition of rat arterial smooth muscle cell proliferation by heparin. I. In vivo studies with anticoagulant and non-anticoagulant heparin. Circ. Res. 46:625634.

10. Castellot, J. J., T. S. Wright, and M. J. Karnovsky. 1987. Regulation of vascular smooth muscle cell growth by heparin and heparan sulfates. Semin. Thromb. Hemostasis. 13:489-503.

11. Dryjski, M., E. Mikat, and T. D. Bjornsson. 1988. Inhibition of intimal hyperplasia after arterial injury by heparins and heparinoid. J. Vasc. Surg. 8:623633.

12. Gospodarowicz, D., and J. Cheng. 1986. Heparin protects basic and acidic FGF from inactivation. J. Cell. Physiol. 128:475-484.

13. Baird, A., and N. Ling. 1987. Fibroblast growth factors are present in the extracellular matrix produced by endothelial cells in vitro: Implications for a role of heparinase-like enzymes in the neovascular response. Biochem. Biophys. Res. Commun. 142:428-435.

14. Bashkin, P., S. Doctrow, M. Klagsbrun, C. M. Svahn, J. Folkman, and I. Vlodavsky. 1989. Basic fibroblast growth factor binds to subendothelial extracellular matrix and is released by heparitinase and heparin-like molecules. Biochemistry. 28:1737-1743.

15. Hondermarck, H., J. Courty, B. Boilly, and D. Thomas. 1990. Distribution of intravenously administered acidic and basic fibroblast growth factors in the mouse. Experientia (Basel). 46:973-974.

16. Neufeld, G., and D. Gospodarowicz. 1985. The identification and partial characterization of the fibroblast growth factor receptor of baby hamster kidney cells. J. Biol. Chem. 260:13860-13868.

17. Reidy, M. A., A. W. Clowes, and S. M. Schwartz. 1983. Endothelial regeneration. V. Inhibition of endothelial regrowth in arteries of rat and rabbit. Lab. Invest. 49:569-575.

18. Fingerle, J., Y. P. T. Au, A. W. Clowes, and M. A. Reidy. 1990. Intimal lesion formation in rat carotid arteries after endothelial denudation in the absence of medial injury. Arteriosclerosis. 10:1082-1087.

19. Clowes, A. W., M. A. Reidy, and M. M. Clowes. 1983. Kinetics of cellular proliferation after arterial injury. I. Smooth muscle growth in the absence of endothelium. Lab. Invest. 49:327-333. 
20. Olson, N. E., S. Chao, V. Lindner, and M. A. Reidy. 1992. The role of basic fibroblast growth factor in intimal smooth muscle cell proliferation. Am. J. Pathol. 140:1017-1023.

21. Reilly, T. M., D. S. Taylor, W. F. Herblin, M. J. Thoolen, A. T. Chiu, D. W. Watson, and P. B. M. W. M. Timmermans. 1989. Monoclonal antibodies directed against basic fibroblast growth factor which inhibit its biological activity in vitro and in vivo. Biochem. Biophys. Res. Commun. 164:736-743.

22. Hardonk, M. J., G. Harms. 1990. The use of 5'-bromodeoxyuridine in the study of cell proliferation. Acta Histochem. (Suppl.) 39:99-108.

23. Whalen, G. F., Y. Shing, and J. Folkman. 1989. The fate of intravenously administered bFGF and the effect of heparin. Growth Factors. 1:157-164.

24. Bârzu, T., J. L. M. L. Van Rijn, M. Petitou, P. Molho, G. Tobelem, and J. P. Caen. 1986. Endothelial binding sites for heparin. Biochem. J. 238:847-854.

25. Majesky, M. W., S. M. Schwartz, M. M. Clowes, and A. W. Clowes. 1987. Heparin regulates smooth muscle $S$ phase entry in the injured rat carotid artery. Circ. Res. 61:296-300.

26. Reilly, C. F., L. M. Fritze, and R. D. Rosenberg. 1986. Heparin inhibition of smooth muscle cell proliferation: a cellular site of action. J. Cell. Physiol. 129:11-19.

27. Thompson, R. W., G. F. Whalen, K. B. Saunders, T. Hores, and P. A.
D'Amore. 1990. Heparin-mediated release of fibroblast growth factor-like activity into the circulation of rabbits. Growth Factors. 3:221-229.

28. Flaumenhaft, R., D. Moscatelli, O. Saksela, and D. B. Rifkin. 1989. Role of extracellular matrix in the action of basic fibroblast growth factor: Matrix as a source of growth factor for long-term stimulation of plasminogen activator production and DNA synthesis. J. Cell. Physiol. 140:75-81.

29. Au, Y. P. T., R. D. Kenagy, and A. W. Clowes. 1992. Heparin selectively inhibits the transcription of tissue-type plasminogen activator in primate smooth muscle cells during mitogenesis. J. Biol. Chem. 267:3438-3444.

30. Jackson, C. L., and M. A. Reidy. 1991. The role of plasminogen activators in arterial smooth muscle cell migration. J. Cell. Biochem. (Suppl.) 15C:128.

31. Clowes, A. W., M. M. Clowes, Y. P. T. Au, M. A. Reidy, and D. Belin. 1990. Smooth muscle cells express urokinase during mitogenesis and tissue-type plasminogen activator during migration in injured rat carotid artery. Circ. Res. 67:61-67.

32. Muthukrishnan, L., E. Warder, and P. L. McNeil. 1991. Basic fibroblast growth factor is efficiently released from a cytosolic storage site through plasma membrane disruptions of endothelial cells. J. Cell. Physiol. 148:1-16.

33. Adamis, P. A., B. Meklir, and N. C. Joyce. 1991. In situ injury-induced release of basic-fibroblast growth factor from corneal epithelial cells. Am. J. Pathol. 139:961-967. 